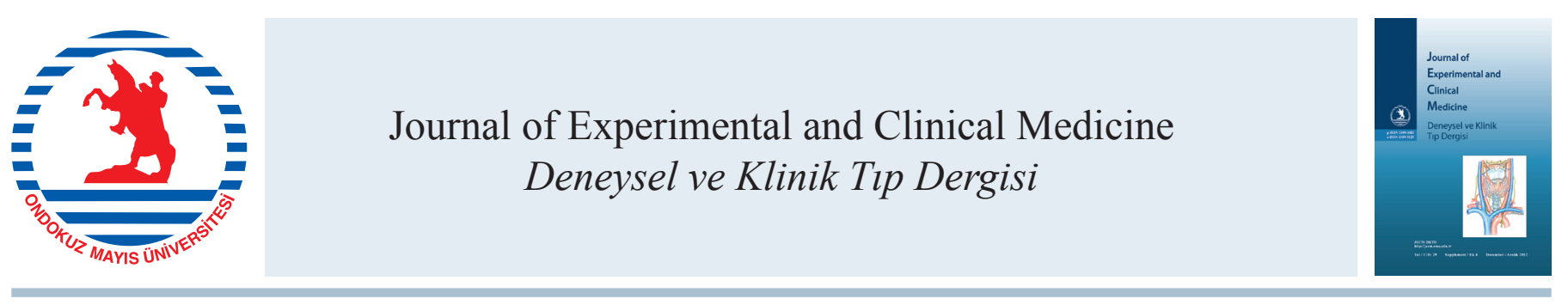

Derleme / Review

doi: $10.5835 /$ jecm.omu.29.s4.021

\title{
İyi diferansiye tiroit kanserleri
}

\section{Well-differentiated thyroid cancers}

\author{
Mahmut Başoğlua ${ }^{a}$ Kağan Karabulut*b \\ ${ }^{a}$ Medicana Hastanesi, Genel Cerrahi Kliniği, Samsun \\ ${ }^{b}$ Ondokuz Mayls Üniversitesi, Tıp Fakültesi, Genel Cerrahi Anabilim Dal, Samsun, Türkiye
}

\begin{tabular}{|c|c|}
\hline MAKALE BİLGÍLERİ & ÖZET \\
\hline Makale geçmişi & İyi diferansiye tiroit kanserleri papiller ve foliküler tiroit kanserleri olarak tanımlanır. \\
\hline Geliş tarihi $\quad: 30 / 05 / 2012$ & Tüm tiroit kanserlerinin $\% 80^{\prime}$ ini oluştururlar ve pimer tedavileri cerrahidir. Bu derle- \\
\hline$: 03 / 12 / 2012$ & $\begin{array}{l}\text { mede iyi differansiye tiroit kanserlerin oluşmasındaki risk faktörlerinden ve prognozu } \\
\text { etkileyen faktörlerden bahsedilmektedir. Total tiroidektomi, lobektomi ve boyun dissek- }\end{array}$ \\
\hline * Yazışma Adresi: & $\begin{array}{l}\text { S1yonu gib1 yapılacak cerrahının seçımı guncel bilgıler eşligınde tartışılmıştır. } \\
\text { J. Exp. Clin. Med., 2012; 29:S329-S332 }\end{array}$ \\
\hline
\end{tabular}

Kağan Karabulut

Ondokuz Mayıs Üniversitesi,

Tıp Fakültesi,

Genel Cerrahi A.B.D

Kurupelit/Samsun

\section{Anahtar Kelimeler:}

Tiroit

Papiller

Foliküler

Diferansiye

Kanser

\section{Keywords:}

Thyroid

Papillary

Follicular

Differentiated

Cancer

\begin{abstract}
Well-differentiated thyroid carcinomas are defined as papillary and follicular thyroid cancers. They consist of $80 \%$ of all thyroid cancers and their primary therapies are surgical. The aim of present review is to present risk factors of occuring well differantial thyroid cancers and the factors that affect prognosis. The choices of surgery including total thyroidectomy, lobectomy and neck dissection are discussed.

J. Exp. Clin. Med., 2012; 29:S329-S332
\end{abstract}

\section{Giriş}

\section{Papiller tiroit karsinomu}

En sık görülen tiroit kanseridir. Kadın erkek oranı 2,5/1' dir. Yaşamın 4. ve 5. dekadlarında kadınlarda görülme sıklığı erkeklere göre daha fazladır (Tuttle ve ark, 2011). Kanıtlanmış risk faktörleri; boyun bölgesine alınmış radyasyon/ radyasyon maruziyeti ve aile hikayesidir. Birinci dereceden yakınlarında tirioit kanserleri olan veya tiroit kanserleri ile ilişkili sendrom bulunanlarda tiroit nodullerinin malignite riski yüksektir. Tiroit kanserleri ile ilişkili sendromlar ailesel polipozis sendromları, Carney Compleksi, MEN tip 2, Werner sendromu ve Cowden sendromu olarak sıralanabilir.

MAPK (mitogen activated protein kinase) yolunda meydana gelen gen mutasyonları ya da yeniden düzenlemeler differansiye tiroit kanserlerinin gelişmesinde ve progresyonunda önemli rol oynarlar (Fagin, 2004). Differansiye tiroit kanserlerinin \% 70 'inde; ret/PTC, NTRK1, Ras ya da BRAF genlerinde mutasyon tespit edilmiştir. (Fagin ve Mitsiades, 2008). Özellikle BRAF mutasyonu olan hastalarda klinik rekürrens, lenf nodu metastazı, tiroit dışı yayılımın daha fazla olduğu gösterilmiştir (Xing ve ark., 2005; Lee ve ark., 2007). Klinik semptomları; hızlı büyüyen fikse tiroit nodülü, yeni başlayan ses kısıklığ 1 ya da vokal kord paralizisi, nodül ile aynı tarafta servikal lenfadenopatidir. Bunun dişında teknolojik gelişmelere paralel olarak boyun bölgesine yapılan taramaların artması sonucu nonpalpabl tiroit kanserlerin sayısında da artış olmaktadır. Papiller tiroit kanserlerinin tanısı genellikle şüpheli nodüle yapılan ince iğne aspirasyon biyopsisi ile konulmaktadır. Papiller tiroit kanserlerinin prognozu çok iyidir. Düşük risk gurubundaki hastalarda kansere bağlı ölüm oranı 
çok düşüktür. Prognozu belirlemek için bir çok prognostik faktör ortaya atılmıştır. Bunların içinde en sık kullanılanı yaş, metastaz, hastalığın yaygınlığı, cinsiyet, tümör çapı ve grade kriterleridir (Tablo 1).

Yaş: 20-45 yaş arasındaki papiller kanserleri uzun dönem iyi prognoza sahiptirler ve kansere bağlı ölüm riski diğer yaş gruplarına göre daha düşüktür (Zaydfudim ve ark., 2008).

Tümör çapı: Tümör çapı arttıkça mortalite oranı artmaktadır. Özellikle bir cm ya da altındaki tümör çapında prognoz çok iyidir ve klinik rekürrense pek rastlanılmaz (Hay ve ark., 1993; Pellegriti ve ark., 2004).

Yumuşak doku invazyonu: Yumuşak doku invazyonu varlığında ölüm riski beş kat artar (Tuttle, 2011).

Uzak metastaz: Uzak metastaz varlığı kötü bir prognostik faktördür. Pulmoner metastaz varlığında 10 yıllık sağ kalım \% 30-50 iken beyin metastazında ortalama sağ kalım bir sene kadardır (Casara ve ark., 1993; Chiu ve ark., 1997) (Tablo 1).

Tablo 1. İyi differansiye tiroit kanserlerinin prognostik risk sinıflaması (AMES/AGES)*

\begin{tabular}{|c|c|c|}
\hline & Düşük risk & Yüksek risk \\
\hline Yaş & $<40$ & $>40$ \\
\hline Cinsiyet & Kadın & Erkek \\
\hline Yayılım & Tiroit dışı yayılım yok & Kapsül invazyonu/tiroit dışı yayılım \\
\hline Metastaz & Yok & Bölgesel/uzak \\
\hline Tümör çapı & $<2 \mathrm{~cm}$ & $>2 \mathrm{~cm}$ \\
\hline Grade & İyi differansiye & Kötü differansiye \\
\hline \multicolumn{3}{|c|}{$\begin{array}{l}\text { *AGES - Age, Grade, Extent of disease, Size } \\
\text { (Yaş, derece, hastalığın yayılımı, çap) } \\
\text { *AMES - Age, Metastasis, Extent of disease, Size } \\
\text { (Yaș, metastaz, hastalığın yayılımı, çap) }\end{array}$} \\
\hline
\end{tabular}

Minör risk faktörleri ise birleşik tümör, 10' dan fazla boyun/mediastinal lenf nodu metastazı, ekstranodal yayılımlı nodal metastaz, erkek cinsiyet ve geçikmiş cerrahi olarak siralanabilir (Leboulleux ve ark., 2005; Lin ve ark., 2009a). Evreleme için genellikle TNM sınıflaması kullanılır. Bu sınıflamanın dışında Amerikan Tiroit Derneğinin yayınladığı kliniko-patolojik sınıflamaya göre üç gruba ayrılır. Düşük riskli grup: Tiroit glandı içinde sınırlı kalan ve agresif histolojiye sahip olmayan tümörler ve post operatif dönemde ${ }^{131}$ I geri alımının olmamas1, orta riskli grup: Mikroskopik invazyon, servikal lenf nodu metastazı, agresif histolojiye sahip tümör (tall cell, insular, kolumnar cell, hurthle cell, foliküler karsinoma), vasküler invazyon, post operatif dönemde ${ }^{131} \mathrm{I}$ uptake olması, yüksek risk grup: Makroskopik tümör invazyonu, tam olmayan rezeksiyon ve uzak metastazdır (Tuttle ve ark., 2010).

\section{Foliküler tiroit karsinomu}

En sık rastlanılan ikinci tiroit kanser tipidir. Diğer differansiye tiroit kanserlerine göre daha geç dönemlerde sıklığı artar. Sıklığı 4. ve 6. dekadlarda artar. Kadın/erkek oranı 3/1 dir (Ries, ve ark., 2004; Tuttle, 2011).

Papiller tiroit kanserlerinin aksine radyasyon maruziyeti, RET-PTC, BRAF mutasyonları çok nadirken, ailesel neoplastik sendromlar ile ilgisi yoktur (Cerilli ve ark., 2002; Xing 2005). RAS mutasyonu, PAX8-PPAR gamma 1 geninde yeniden düzenlenme etiyolojide rol oynar. RAS mutasyonu foliküler kanserlerin \% 40' inda görülmesine rağmen foliküler kanserler için spesifik değildir. RAS mutasyonunun varlığ kanserin agresifliği ve yüksek mortalitesi ile ilgilidir (Medema ve ark., 1993; Garcia-Rostan ve ark., 2003). PAX8-PPAR gamma 1 geninde yeniden düzenlenme foliküler adenomların $\% 10$ ' unda foliküler kanserlerin $\% 41^{\prime}$ inde görülür (Fagin, 2005). Diğer suçlanan faktörler ise p53, c-myc, c-fos, TSH reseptör mutasyonlarıdır. İyot eksikliğinin, foliküler kanser gelişiminde rol oynayabileceğini gösteren çalışmalar bulunmaktadır (Pendergrast ve ark., 1961; Nikiforov, 2004). Hastalar, tiroit nodülü, az sıklıkla olmakla beraber servikal lenf nodları ya da hipertiroidizm semptomları ile başvururlar. Bazen de uzak metastazlara bağlı semptomlar ile başvururlar. İnce iğne aspirasyon biyopsisi papiller kanserin aksine foliküler kanserlerin teşhisinde yeterli değildir. İnce iğne aspirasyon biyopsisi foliküler kanser ile adenomun ayrımında yardımcı olmaz. Bu nedenle şüpheli nodülü bulunan ve ince iğne biyopsisi folüküler lezyon olarak gelen yaşlı hastalar malignite riski yüzünden ameliyat edilmelidir.

Lenf nodu tutulumu, papiller tiroid kanserin aksine daha az rastlanır ve yaygın değildir. Olguların \% 8-13' ünde lenf nodu tutulumu görülür (Tuttle, 2011). Foliküler kanserler hematojen yol ile yayılırlar. Uzak metastaz olguların \% 10-15 ' inde görülür. Tümör çapı iki $\mathrm{cm}$ den küçük olan tümörlerde uzak metastaz olması beklenmez (Machens ve ark., 2005). En s1k metastaz kemik ve akciğerleredir. Daha az sıklıkla beyin, karaciğer, safra kesesi ve cilt metastazı görülebilir (Grebeve ve Hay, 1995).

\section{Prognostik özellikleri:}

Prognostik özellikleri diğer iyi differansiye tiroit kanserlerine benzerdir. Prognoz belirlemede birçok sınıflama sistemi kullanılsa da en sık kullanılanlar AMES ve AGES sınıflamalarıdır. Diğer differansiye kanserlerine göre daha yaşlı hastalarda, agresif klinik gidişe, uzak metastaz eğilimi ve yüksek mortaliteye sahiptir. Önemli prognostik faktörleri evre, yaş, tümörün karakteri (tümör boyutu, vasküler invazyon, kapsül yayılımı, uzak metastaz)' dır. Yaş önemli bir prognostik faktördür (Grebeve, 1995). Yaşın artması ile beraber yaşam sürelerinde azalış, tümör agresifliğinde artış ve radyoaktif iyot tedavisine cevap azalır. Erken rekürrens yaşlı erkek hastalarda sık görülür (Lin ve ark., 2009b).

\section{İyi diferansiye tiroit kanserlerin cerrahi tedavisi}

İyi diferansiye tiroit kanserlerin primer tedavi yöntemi cerrahidir. Yapılacak cerrahi hastaların çoğunluğunda total tiroidektomi/totale yakın tiroidektomi ya da tek taraflı lobektomidir. Günümüzde subtotal tiroidektomi bu tür hastaların tedavisinde önerilmemektedir. Bu iki cerrahi yaklaşımdan hangisinin uygulanacağı hastanın klinik özelliklerine göre değişmektedir. Yapılan çalışmalarda \% 36-85 hastada her iki tiroit lobunda papiller kanser odağının olması, \% 5-10 hastada rekürren tiroit kanserinin karşı lobdan çıkması, rekürren kansere bağlı ölüm oranının 1,5 kat artması, radyoaktif iyot ablasyon tedavisini kolaylaştırması, serum tiroglobülin düzeyinin post operatif dönemde takip amaçlı kullanılmasını sağlaması ve ameliyat sonrası takiplerde ameliyat bölgesinin radyolojik takibinin daha kolay olması nedeniyle günümüzde total/totale yakın tiroidektomi bu hastaların cerrahi tedavisinde en sık kullanılan ve önerilen cerrahidir (Smith ve ark., 1963; Tollefsen ve Decosse, 1963; Silverberg ve ark., 1970; Katoh ve ark., 1992; Pacini, ve ark., 2001; Kim ve ark., 2004; 
Shattuck ve ark., 2005). Yapılan retrospektif çalışmalar da göstermiştir ki primer tümör çapı bir cm ya da yukarısı ise total tiroidektomi sonrası rekurrens ve ölüm riski azalmaktadır (Bilimoria ve ark., 2007). Total tiroidektomi tümör çap1 bir $\mathrm{cm}$ ve üzeri ise, tiroit dışı tulum/metastaz ya da hastanın öyküsünde boyun bölgesine radyasyona maruz kalma öyküsü varsa total veya totale yakın tiroidektomi yapılması önerilmektedir (Mazzaferri ve Jhiang, 1994).

Tek taraflı lobektomi ve ishmektomi tümör çapı bir cm altında/düşük riskli hastalarda üç $\mathrm{cm}$ ve altı ise ve de tek lobda lokalize bir tümör ise önerilmektedir. Yapılan bir çalışmada bu tip hastalarda 30 yıllık yaşam süresinin \% 100 olduğu tespit edilmiştir (Mazzaferri ve Jhiang, 1994). Bir başka durumda şüpheli lezyonu bulunan fakat kanser tanısı konulamamış hasta grubudur ki bu durumda hastalara tek taraflı lobektomi ve ishmektomi uygulanmalı ve kesin patoloji sonucuna göre hastanın tedavisi tekrar gözden geçirilmelidir. Çünkü bu gibi durumlarda hastaların \% 60' inda patoloji sonuçları iyi huylu olduğu gösterilmiştir (Tyler ve ark., 1994). Boyun disseksiyonu papiller karsinomla beraberinde klinik olarak tespit edilmişse boyun disseksisyonu yapılması tavsiye edilmektedir. Ayrıca Amerikan Tiroit Derneği ileri tümörlerde (tümör çapı $>4 \mathrm{~cm} /$ ekstratiroidal yayılım varsa) profilaktik santral kompartman lenf nodlarının profilaktik disseksiyonu önerilmektedir (National Comprehensive Cancer Network; Amerikan Tiroid Derneği )(NCCN; ATA).

\section{KAYNAKLAR}

American Thyroid Association (ATA) Guidelines Taskforce on Thyroid Nodules and Differentiated Thyroid Cancer, Cooper D.S., Doherty, Gerard M. D. Haugen, B.R., Kloos, R.T., Lee, S.L., Mandel, S.J., Mazzaferri, E.L., McIver, B., Pacini F., Schlumberger, M., Sherman, S.I., Steward, D.L., Tuttle, R.M., 2009. Revised American Thyroid Association management guidelines for patients with thyroid nodules and differentiated thyroid cancer. Thyroid. 19, 1167.

Bilimoria, K.Y., Bentrem, D.J., Ko,C.Y., 2007. Extent of surgery affects survival for papillary thyroid cancer. Ann. Surg. $246,375$.

Casara, D.,Rubello, D., Saladini, G., Masarotto, G., Favero, A., Girelli, M.E., Busnardo, B.,1993. Different features of pulmonary metastases in differentiated thyroid cancer: Natural history and multivariatestatistical analysis of prognostic variables. J. Nucl. Med. $34,1626$.

Cerilli, L.A., Mills, S.E., Rumpel, C.A., Dudley, T.H., Moskaluk, C.A.,2002. Interpretation of RET immunostaining in follicular lesions of the thyroid. Am. J. Clin. Pathol. 118, 186.

Chiu, A.C., Delpassand, E.S., Sherman, S.I.,1997. Prognosis and treatment of brain metastases in thyroid carcinoma. J. Clin. Endocr. Metab. 82, 3637.

Fagin, J.A.,2004. How thyroid tumors start and why it matters: kinase mutants as targets for solid cancer pharmacotherapy. J. Endocrinol. 183, 249.

Fagin, J.A., 2005. Molecular genetics of tumors of thyroid follicular cells. In: Werner and Ingbar's the thyroid: a fundamental and clinical text, Braverman, L.E., Utiger, RD (Eds), Philadelphia, PA. pp. 909.

Fagin, J.A., Mitsiades, N., 2008. Molecular pathology of thyroid cancer: Diagnostic and clinical implications. Best Pract. Res. Cl. En. $22,955$.

Garcia-Rostan, G., Zhao, H., Camp, R.L., Pollan, M., Herrero, A., Pardo, J., Wu, R., Carcangiu, M.L., Costa, J., Tallini, G., 2003.Rasmutations are associated with aggressive tumor phenotypes and poor prognosis in thyroid cancer. J. Clin. Oncol.21, 3226.

Grebe, S.K., Hay, I.D., 1995. Follicular thyroid cancer. Endocrin. Metab. Clin. 24,761.

Hay, I.D.,Bergstralh, E.J., Goellner, J.R., Rsold, J.R., Grant, C.S., 1993. Predicting outcome in papillary thyroid carcinoma: Development of a reliable prognostic scoring system in a cohort of 1779 patients surgically treated at one institution during 1940 through 1989 . Surgery. 114,1050 .

Katoh, R., Sasaki, J., Kurihara, H., Suzuki, K., Iida, Y., Kawaoi, A.,1992. Multiple thyroid involvement (intraglandular metastasis) in papillary thyroid carcinoma. A clinicopathologic study of 105 consecutive patients. Cancer. 70, 1585.

Kim, E.S., Kim, T.Y., Koh, J.M., Hong, S.J., Kim, W.B., Shong, Y.K., 2004. Completion thyroidectomy in patients with thyroid cancer who initially underwent unilateral operation. Clin. Endocrinol. (Oxf) 61, 145.

Lee, J.H., Lee, E.S., Kim, Y.S., 2007. Clinicopathologic significance of BRAF V600E mutation in papillary carcinomas of the thyroid: A metaanalysis. Cancer. 110, 38.

Leboulleux, S.,Rubino, C., Baudin, E., Hartl, D.M., Bidart, J.M., Travagli, J.P., Schlumberger, M., 2005. Prognostic factors for persistent or recurrent disease of papillary thyroid carcinoma with neck lymphnode metastases and/or tumor extension beyond the thyroid capsule at initial diagnosis. J. Clin. Endocr. Metab. 90, 5723.

Lin, J.D., Chao, T.C., Hsueh, C., Kuo, S.F., 2009a. High recurrent rate of multicentric papillary thyroid carcinoma. Ann. Surg. Oncol. 16, 2609.

Lin, J.D., Hsueh, C., Chao, T.C., 2009b. Early recurrence of papillary and follicular thyroid carcinoma predicts a worse outcome. Thyroid 19, 1053.

Machens, A., Holzhausen, H.J., Dralle, H., 2005. The prognostic value of primary tumor size in papillary and follicular thyroid carcinoma. Cancer. 103, 2269

Mazzaferri, E.L., Jhiang, S.M.,1994. Long-term impact of initial surgical and medical therapy on papillary and follicular thyroid cancer. Am. J. Med. 97, 418.

Medema, R.H., Bos, J.L., 1993. The role of p21ras in receptortyrosine kinase signaling. Crit. Rev. Oncog. 4, 615.

National Comprehensive Cancer Network (NCCN) guidelines. Available at: www.nccn.org (Accessed on October 13, 2011).

Nikiforov, Y.E., 2004. Genetic alterations involved in the transition from well-differentiated to poorly differentiated and anaplastic thyroid carcinomas. Endocr. Pathol. 15, 319.

Pacini, F., Elisei, R., Capezzone, M., Miccoli, P., Molinaro, E., Basolo, F., Agate, L., Bottici, V., Raffaelli, M., Pinchera, A., 2001. Contralateralpapillary thyroid cancer is frequent at completion thyroidectomy with no difference in low- and high-risk patients. Thyroid. $11,877$.

Pellegriti, G., Scollo, C., Lumera, G., Regalbuto, C., Vignerı, R., Belfiore, A., 2004. Clinical behavior and outcome of papillary thyroid cancers smaller than 1,5 cm in diameter: Study of 299 cases. J. Clin. Endocr. Metab. 89, 3713.

Pendergrast, W.J.,Milmore, B.K., Marcus, S.C.,1961. Thyroid cancer and thyrotoxicosis in the United States: Their relation to endemic goiter. J. Chronic Dis. 13, 22.

Ries, L.A.G., Eisner, M.P, Kosary, C.L, Hankey, B.F., Miller, B.A., Clegg, L., Mariotto, A., Fay, M.P., Feuer, E.J., Edwards, B.K., 2004. (Eds), SEER Cancer Statistics Review. National Cancer Institute, Bethesda, MD 1975-2001. NM scan on nodule: Hegedusarticle NEJM. http://seer. 
cancer.gov/csr/1975_2001/, (Accessed on 22.10.2005).

Rosai, J.,Carcangiu, M.L., De Lellis, R.A., Tumors of the thyroid gland. In: Atlas of tumor pathology, 3rd series, fas 5. AFIP, Washington.

Shattuck, T.M., Westra, W.H., Ladenson, P.W., Arnold, A., 2005. Independent clonalorigins of distinct tumor foci in multifocal papillary thyroid carcinoma. New Engl. J. Med. 352, 2406.

Silverberg, S.G.,Hutter, R.V., Foote, F.W. Jr., 1970. Fatal carcinoma of the thyroid: Histology, metastases, and causes of death. Cancer.25, 792.

Smith, R.R., Frazell, E.L., Caulk, R., Holinger P.H., Russell, W.O., 1963. The american joint committee'sproposed method of stage classification and end-result reportıngapplied to 1,320 Pharynx Cancers. Cancer.16, 1505.

Tuttle, R.M.,Tala, H., Shah, J., Leboeuf, R., Ghossein, R., Gonen, M., Brokhin, M., Omry, G., Fagin, J.A., Shaha, A., 2010. Estimating risk of recurrence in differentiated thyroid cancer after total thyroidectomy and radioactive iodine remnantablation: Using response to therapy variables to modify the initial risk estimatespredicted by the new American Thyroid Association staging system. Thyroid. $20,1341$.

Tollefsen, H.R., Decosse, J.J., 1963. Papillarycarcinoma of the thyroid. recurrencein the thyroid gland after initial surgical treatment. Am. J. Surg. 106, 728 .

Tyler, D.S.,Winchester, D.J., Caraway, N.P.,Hickey, R.C., Evans, D.B.1994. Indeterminate fine-needle aspiration biopsy of the thyroid: İdentification of subgroups at high risk for invasive carcinoma. Surgery. 116, 1054.

Tuttle, R.M, 2011. uptodate/overview of papiller thyroid cancer.

Xing, M., 2005. BRAF mutation in thyroid cancer. Endocr Relat. Cancer. 12, 245.

Xing, M.,Westra, W.H., Tufano, R.P., Cohen,Y., Rosenbaum, E., Rhoden, J.K., Carson, K.A., Vasko,V., Larin, A.,Tallini, G., Tolaney, S., Holt, E.H., Hui, P.,Umbricht, C.B.,Basaria, S.,Ewertz, M., Tufaro, A.P., Califano, J.A., Ringel, M.D.,Zeiger, M.A.,Sidransky, D., Ladenson, P.W., 2005. BRAF mutation predicts a poorer clinical prognosis for papillary thyroid cancer. J. Clin. Endocr. Metab. $90,6373$.

Zaydfudim, V., Feurer, I.D., Griffin, M.R., Phay, J.E., 2008. The impact of lymphnode involvement on survival in patients with papillary and follicular thyroid carcinoma. Surgery. 144, 1070. 